場凝聚点发出的。这显得是很奇异的。 ${ }^{[4]}$

若使这种看法属实, 可以解释为什么 200 兆周电 波輻射当耀玨懪发时, 有突增的强度。这是因为伴随 太阳形翟出現的粒子萧发射到上述的凝聚点, 使得它 的电子密度突增的結果。

本文的結果扑不局限于討論 200 兆周和电子的束 䋨态的关系。在强磁場中, 稹子也可能发出无䋐电 波。太阳上的其他电波輻射, 也应有由此效应引起的 一部分。

\section{陈 彪}

（紫金山天文台）

1959 年 6 月 8 日

[1] Блохинуев, А.И., Основы Квантовой Механнки, ГИТТЛ 1949 стр. 223-225

[2] Landau, L., and Lifshilz, E., The Classical Theory of Fields 交通书店影印 pp. 191-192

[ 3 ] Unsöld, A., Physik der Sternatmosphären, Verlag Springer, 1955 ss177-181

[4] Pawsey, J.L. and Smerd, S.F., Solar Radio Emission, The Sun(ed. Kuiper) 1954 pp467-529

\section{硝酸鎘絡合物的极譜研究}

硝酸根与金属离子間的的絡合作用徍往被人們所 忽視, 很多作者常用硝酸根作为維持离子强度的悄性 电解稹, 来研究溶液中的絡合反应。例如 Hume ${ }^{[1]}$ 和 Leonard [2]等曾用硝酸根作为悎性电解稹来分別測定鎘 与亚釷和硫酸根間的絡合反应, 由于硙酸根和金属

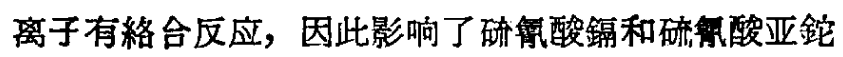
絡合物的稳定常数的測定。对硫钼酸鉛和硫氧酸鋅絡 合物也有类似的情况。

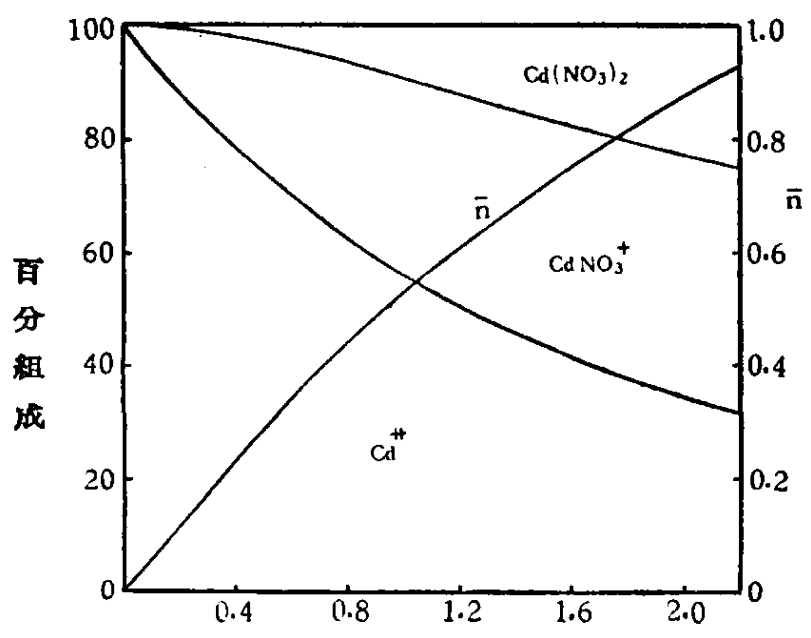

确酸根的克分子浓度
为了确定硝酸根和金属离子間的絡合作用，我們 用极譜法測定了硝酸鎘絡合物的稳定常数。稳定常数 的計算按报告 [ [3] 所迅方法处理，实驗方法見报告 ${ }^{11}{ }^{[4]}$ 和 IV ${ }^{[5]}$, 湘定 $\Delta E_{1 / 2}$ 的俱差在 $\pm 0.2 \mathrm{mV}$ 以 内。在高氯酸鈵䊒持离子强度 $\mu=3$ 的溶液中証明 坷 $\mathrm{Cd}^{++}, \mathrm{CdNO}_{3}{ }^{+}$和 $\mathrm{Cd}\left(\mathrm{NO}_{3}\right)_{20}$ 稳定常数为 $\mathrm{K}_{1}=0.62$, $\mathrm{K}_{2}=0.16\left(25^{\circ}\right)$ 。下图表示在不同硝酸根浓度的溶液中 硝酸鎘絡离子的百分組成和平均絡合数 $\bar{n}_{\text {。 }}$

硝酸鎘絡合物早在 1912 年會被 Noyes ${ }^{[6]}$ 等用电 导法研究过，1930 年 Rigellato[7] 等仍用电导法研 究，指明溶液中有 $\mathrm{CdNO}_{3}{ }^{+}$絡离子，在 $18^{\circ} \mathrm{C}$ 时稳定 常数为 $K_{1}=2.76$ 。1941 年 Leden ${ }^{[8]}$ 用电势法䃑究了 这一体系, 硝酸根浓度在 $0-0.6 \mathrm{M}$ 范围內, 測得溶 液中有 $\mathrm{CdNO}_{3}{ }^{+}$絡离子, 稳定常数为 $\mathrm{K}_{1}=1.29$ 。无 論 Righellato 和 Leden 等測定时使用硝酸根浓度都很 低, 因此不易察覚 $\mathrm{Cd}\left(\mathrm{NO}_{3}\right)_{2}$ 分子的传在。我們采用 硝酸根浓度范围在 $0-2 \mathrm{M}$, 发現溶液中除了 $\mathrm{CdNO}_{3}{ }^{+}$ 离子外份有 $\mathrm{Cd}\left(\mathrm{NO}_{3}\right)_{2}$ 分子, 且証明硝酸根浓度在 $2 \mathrm{M}$ 范围內, 鎘和硝酸根絡合的最大配位数为 2 。

从分们图中看出, 硝酸根浓度为 $0.6 \mathrm{M}$ 时, $\mathrm{Cd}\left(\mathrm{NO}_{3}\right)_{2}$ 分子的含量約占 $4 \%$, 而硝酸根浓度为 $2 \mathrm{M}$ 时, $\mathrm{Cd}\left(\mathrm{NO}_{3}\right)_{2}$ 含量将超过 $20 \%$ 。因此 Righellato 和 Leden 詮为在鎘和硝酸根溶没中只有 $\mathrm{Cd}\left(\mathrm{NO}_{3}\right)^{+}$的铪 据是不充分的，他們求得稳定常数較我們为大，亦肉 他們把 $\mathrm{Cd}\left(\mathrm{NO}_{3}\right)_{2}$ 的絡合作用归結为 $\mathrm{CdNO}_{3}{ }^{+}$之故。

本文除了对鎘和硝酸根間絡合作用呼究外，还討 論了因使用不同的底液，絡合物的稳定常 数 亦不相 同，抹指出在相同的实驗条件下（如同一离子强度、 和溫度等)以不同底液作为介稹时稳定常数的換算法。

\section{蔣洪圻 徐光害 \\ (北京大学化学系) \\ 1959 年 5 月12日}

[1] D. N. Hume, D.D.DeFord and G.C.B.Cave, J. Am. Chem. Soc., 73, 5323 (1951).

[2] G. W. Leonard, M. E. Smith and D. N. Hume, J. Phys. Chem., 60, 1493 (1956).

[3] 俆光先,任觉,严售粹，化学学报 22，447 (1956)。

[4] 蔣洪圻和徐光先, 化学学报 23, 196 (1957)。

[5]徐光先和蔣洪圻,化学学报 24, 277 (1958)。

[6] A.A.Noyes and K. G. Falk, J. Am. Chem. Soc.,34, 454 (1912).

[ 7 ] E. C. Righellato and C. W. Davies, Trans. Faraday Soc., 26, 592 (1930).

[8] I.Leden, Z.Phys. Chem., 188A, 160 (1941). 